\title{
LINAC-based Fractionated Stereotactic Radiotherapy for Residual and Recurrent Nasopharyngeal Carcinoma in the Era of Intensity-modulated Radiotherapy: A 10-year Experience
}

\author{
TTS Lau ${ }^{1}$, LL Chan ${ }^{1}$, ELM Yu ${ }^{2}$, JWY Lai ${ }^{1}$, KT Yuen ${ }^{1}$, ACK Cheng1 \\ ${ }^{I}$ Department of Oncology, Princess Margaret Hospital, Laichikok, Hong Kong \\ ${ }^{2}$ Clinical Research Centre, Princess Margaret Hospital, Laichikok, Hong Kong
}

\begin{abstract}
Introduction: We reviewed the use of frameless linear accelerator-based fractionated stereotactic radiotherapy (FSRT) in a single centre as salvage treatment for patients with nasopharyngeal carcinoma with local failure.

Methods: We retrospectively reviewed the data of all patients with residual or recurrent nasopharyngeal carcinoma who had undergone salvage therapy with FSRT at our institution between 2008 and 2017. Survival data were analysed by the Kaplan-Meier method. Univariate analyses for survival outcomes were performed using the Cox proportional hazards model. Severe late radiation toxicities were assessed.

Results: Of the 49 patients included, 44 (90\%) had previously received intensity-modulated radiotherapy as primary treatment. The median FSRT dose was 18 Gy in three fractions for residual disease, and 48 Gy in six fractions for recurrent disease. Median follow-up was 41.1 months. The 3-year local control rate, progression-free survival (PFS), disease-specific survival, and overall survival (OS) for patients with residual disease $(n=34)$ were $78.9 \%, 66.2 \%$, $82.2 \%$, and $74.0 \%$, respectively. Those for patients with recurrent disease $(n=15)$ were $68.2 \%, 40.0 \%, 58.7 \%$, and $46.7 \%$, respectively. Using FSRT, a gross tumour volume of $\leq 16 \mathrm{~mL}$ of residual disease was associated with longer PFS and OS. N3 nodal staging status was associated with poorer PFS in the residual disease group. Severe late complications occurred in 12 patients (24\%), including one patient from the residual disease group and four patients from the recurrent disease group with fatal haemorrhage (10\%).

Conclusion: Using this less-invasive and resource-friendly technique, the clinical outcomes from our centre were comparable to those in the literature.
\end{abstract}

Key Words: Dose fractionation, radiation; Nasopharyngeal carcinoma; Neoplasm, residual; Salvage treatment

\footnotetext{
Correspondence: Dr TTS Lau, Department of Oncology, Princess Margaret Hospital, Laichikok, Hong Kong

Email: tracylts@ha.org.hk
}

Submitted: 14 Sep 2018; Accepted: 22 Oct 2018.

Contributors: TTSL designed the study; TTSL acquired the data; TTSL, LLC and ELMY analysed the data; TTSL drafted the manuscript. All authors critically revised the manuscript for important intellectual content. All authors had full access to the data, contributed to the study, approved the final version for publication, and take responsibility for its accuracy and integrity.

Conflicts of Interest: The authors have no conflict of interest to declare.

Funding/Support: This research received no specific grant from any funding agency in the public, commercial, or not-for-profit sectors.

Ethics Approval: This retrospective study was approved by the Kowloon West Cluster Research Ethics Committee (Ref KW/EX-18-069(123$08)$ ). 


\title{
中文摘要
}

\section{調強放療年代的殘存及復發性鼻咽癌的直線加速器分段立體定向 放射治療：10年經驗回顧}

\author{
劉芷珊、陳瓏、余洛汶、黎詠宇、袁錦堂、鄭志堅 \\ 引言 : 回顧無框架式直線加速器分段立體定向放射治療 (FSRT) 在一所本地醫院作為鼻咽癌局部失 \\ 敗挽救性治療的療效和安全性。 \\ 方法 : 回顧2008年至2017年在本院接受FSRT治療的殘存及復發性鼻咽癌患者, 評估腫瘤反應和放療 \\ 毒性。使用Kaplan-Meier法計算生存數據, 以Cox比例風險回歸模型分析存活率風險因子。 \\ 結果：共納入49名患者，當中44名（90\%）接受調強放療作為首次治療手段。殘存性鼻咽癌（34 \\ 名) FSRT中位劑量為 $18 \mathrm{~Gy} / 3$ 次, 復發性鼻咽癌中位劑量為 $48 \mathrm{~Gy} / 6$ 次。中位隨訪期為 41.1 個月。殘存 \\ 性鼻咽癌（15名）3年局部控制率為 $78.9 \%$, 無惡化存活率為 $66.2 \%$, 無瘤存活率為 $82.2 \%$, 總存活率 \\ 為 $74 \%$ 。復發性鼻咽癌3年局部控制率為 $68.2 \%$, 無惡化存活率為 $40 \%$, 無瘤存活率為 $58.7 \%$, 總存 \\ 活率為 $46.7 \%$ 。在殘存性鼻咽癌患者中, 腫瘤體積少於 $16 \mathrm{~mL}$ 與較長無惡化存活期和總存活率期有關 \\ 聯, 而N3則與較短無惡化存活期有關聯。12名病人 ( $24 \%)$ 出現嚴重後期併發症, 當中包括一名殘 \\ 存性鼻咽癌患者和四名復發性鼻咽癌患者出現致命性出血（10\%）。
}

結論 : 作為相對低入侵性及節省資源的放射治療方法, 本研究患者的治療效果和文獻記載相若。

\section{INTRODUCTION}

Nasopharyngeal cancer (NPC) is common in Southeast Asia, especially Southern China. Despite a continued decreasing trend, the latest reported incidence in Hong Kong is 12 per 100000 , ranking tenth among the commonest cancers in the region. ${ }^{1}$

Intensity-modulated radiotherapy (IMRT) allows remarkable improvement in dose conformity compared with two-dimensional or three-dimensional conformal radiotherapy (RT), and IMRT use is associated with better survival outcomes and less treatment toxicity in NPC. ${ }^{2}$ In modern series using IMRT, the reported local failure rate is $5 \%$ to $15 \%$ for earlier stages, but is much higher, $15 \%$ to $45 \%$, for T4 disease. ${ }^{3,4}$ The Hong Kong Nasopharyngeal Cancer Study Group (HKNPCSG) 1301 study evaluated more than 3000 patients treated with primary IMRT. Despite a low overall local recurrence rate of $3.9 \%$, the 8 -year actuarial local failure-free survival was only $71.6 \%$ for $\mathrm{T} 4$ disease, in contrast to the satisfactory outcomes of T1 to T3 disease (87\%-92\%). ${ }^{5}$

Management of local failure requires consideration of multiple factors, including location and extent of disease, availability of modality and expertise, as well as the patients' preferences and co-morbidities. An operative approach with nasopharyngectomy has been reported to offer favourable local control, but is often challenging due to the complex anatomy. A high level of surgical expertise is required, and such surgery is only feasible for patients with lower rT stages (rT1 to limited rT3) ${ }^{6-8}$ It may also be less favoured for patients with significant concerns to operative risks and cosmetic result especially for open surgery. Nonoperative approaches include reirradiation with IMRT, stereotactic radiotherapy (single or multiple fractions), brachytherapy (intracavitary or interstitial), and photodynamic therapy, with the latter two only for $\mathrm{T} 1$ to early T2 lesions. Chemotherapy may be added as a component of salvage treatment but should not be used alone if long-term control is pursued. ${ }^{6-8}$

Stereotactic single-fraction radiotherapy, also known as stereotactic radiosurgery (SRS), was first used as a treatment option for recurrent NPC in the late 1990s. However, the use of stereotactic frames with neurosurgery expertise was almost always required, which caused logistic challenges in practice, and the frames themselves were uncomfortable. Fractionated stereotactic radiotherapy (FSRT) adopts the concept of precision in SRS but delivers the dose in multiple fractions, resulting in a better therapeutic ratio based on radiobiology principles. A matched cohort analysis 
showed better 3-year local failure-free survival rates with FSRT than with single-fraction SRS, especially for recurrent and non-T1 disease. ${ }^{9}$ The concerns of FSRT being more resource-intense and the issue of interfractional reproducibility have been tackled by advancements in treatment delivery speed and in stereotactic systems. LINAC-based frameless stereotactic systems are now commercially available, allowing FSRT to be delivered in a less-invasive and resource-friendly manner.

\section{METHODS}

\section{Patients}

The data of all patients with NPC local failure treated with reirradiation by FSRT in our institution between 2008 and 2017 were retrospectively reviewed. Patients with residual disease (residual tumour or relapse within 6 months of primary RT completion) and recurrent disease (relapse beyond 6 months of primary RT completion) were analysed.

\section{Primary Treatment Methods}

The primary RT treatment was a course of highdose IMRT, delivering 70 Gy to the gross tumour, lymphadenopathy and nasopharynx, $60 \mathrm{~Gy}$ to the highrisk subclinical sites and lymphatic regions, and $54 \mathrm{~Gy}$ to the low-risk lymphatic regions using simultaneous integrated boosts, one fraction per day on weekdays to total 33 to 35 fractions. Concurrent chemotherapy was administered to patients with stage III-IV and T2N1 disease (as an option for high-risk stage II).

\section{Assessment of Residual or Recurrent Disease} For the residual disease group, all patients had completed radical RT as the primary treatment of NPC. Their tumour response was assessed by two fibreoptic nasopharyngoscopy sessions performed 8 and 10 weeks after completion of RT. A systematic six-site (bilateral roofs, lateral walls, and posterior walls) mapping biopsy of the nasopharynx was performed during each session, and remission was defined as two consecutive negative biopsies at each site. A positive biopsy at any one site in any of these two sessions warranted an additional session 12 weeks after RT. If the repeated biopsy was positive, the patient was considered to harbour persistent residual disease and salvage treatment (FSRT) was initiated, accounting for the residual disease group in this study. ${ }^{10}$

All patients considered free from persistent disease were followed up routinely with clinic visits and physical examinations. Investigations, such as fibreoptic nasopharyngoscopy and magnetic resonance imaging (MRI) were arranged on symptom presentation or abnormal physical findings. In the recurrent disease group, systemic re-staging was mandatory, with most patients undergoing positron-emission tomography and computed tomography (CT) scan to allow planning of FSRT.

\section{Fractionated Stereotactic Radiotherapy Technique, Planning and Treatment Delivery} FSRT was performed using an Eclipse IMRS Planning System (Varian Medical Systems; Palo Alto [CA], United States), capable of delivering both cone and multileaf collimation-based IMRT by the Varian Clinac $\AA$ iX linear accelerators.

Gross tumour volume (GTV) was contoured on the CT images using all available imaging data gathered by $\mathrm{CT}$, MRI and positron-emission tomography/CT, as well as by endoscopic mapping. The planning target volume was generated by adding a 2-to-3-mm margin to the GTV . No elective reirradiation of regional lymph nodes was performed. Planning organ-at-risk (OAR) volumes were routinely contoured for critical neurological structures, including the brainstem, optic chiasm, optic nerves, and spinal cord by adding 3-mm margins to the optic chiasm, optic nerves and brainstem, and 5-mm margins to the spinal cord. In cases where the high-dose region was in close proximity to these OARs, smaller planning OAR volume margins (1-2 $\mathrm{mm}$ ) would be used, where stringent image-guided treatment verification would be practised. The patients were informed of the relatively higher risk. Two treatment fractions per week, with an interfractional interval of at least 24 hours, were administered.

Different total doses and fractionations of FSRT were chosen based on the type of relapse (with residual disease considered more radiosensitive than recurrent disease), tumour extent, cumulative radiation dose for critical structures, and time interval from previous RT. For patients whose time interval between two RT courses was $>1$ year, a $33 \%$ to $50 \%$ dose tolerance recovery of central nervous system structures from the initial treatment course was assumed. ${ }^{11}$ No patient received a cumulative lifetime biologically equivalent dose in 2-Gy fractions (EQD2) of $>60$ Gy to the brainstem ${ }^{12}$ or optic chiasm, or 50 Gy to the spinal cord..$^{13}$

\section{Follow-up}

After FSRT, tumour response was assessed by nasopharyngoscopy (with biopsy) and MRI. Regular 
follow-up included clinical examination and toxicity assessment. Further imaging or endoscopy was arranged if clinically indicated.

\section{Data Collection and Statistical Analyses}

The cut-off date for data collection was 15 August 2018. The duration of follow-up was calculated from the date of completion of reirradiation to either the day of death or the day of the last follow-up.

The data were analysed to determine the pathological complete response rate to FSRT, local control rate, progression-free survival (PFS), disease-specific survival (DSS), and overall survival (OS).

Actuarial rates were calculated using the KaplanMeier method, and differences were compared using the log-rank tests. Univariate analyses using the Cox proportional hazards regression model were utilised to test the significance of different prognostic factors. Patient factors (age, sex, histological type, relapse-free interval for recurrent disease, time from pathological diagnosis of local failure to completion of treatment), tumour factors (initial $\mathrm{T}$ and $\mathrm{N}$ stage, recurrent $\mathrm{T}$ and $\mathrm{N}$ stage, FSRT GTV), and treatment factors (cumulative concurrent cisplatin dose, dose of FSRT [biologically effective dose with $\alpha / \beta=10 \mathrm{~Gy} ; \mathrm{BED}_{10}$ ]) were included in univariate analyses. Time-dependent receiver operating characteristic analysis was used to determine the cut-off values of FSRT GTV in predicting survival outcome.

All analyses were performed using SPSS (Windows version 16.0; SPSS Inc, Chicago [IL], United States) and $\mathrm{R}$ (Version 3.5.1; www.r-project.org). The criterion for statistical significance was set at $\mathrm{p}<0.05$.

\section{RESULTS}

\section{Patient Characteristics}

All 49 patients with NPC local failure treated with reirradiation by FSRT in our institution were retrospectively reviewed. The median follow-up for the entire cohort was 41.1 (range, 3.7-118.1) months. Among them, 34 had residual disease and 15 had recurrent disease.

Overall, most tumours $(>90 \%)$ were of the undifferentiated subtype (World Health Organization type III). For the residual tumour group, more than half of the patients had had locally advanced (T3/4) tumours at presentation. All patients had salvage FSRT completed within 6 months after residual disease was confirmed. In the recurrent disease group, most tumours were rT3 $(53.3 \%)$. Five patients with recurrent disease had concomitant nodal recurrences (all N1-2); two were in the retropharyngeal region, which were treated with the same course of FSRT; three were in the cervical region and had undergone radical neck dissection. The median time from completion of primary treatment to recurrence was 21.5 months (range, 7.2-182.3 months). Before FSRT, 14 of 15 patients had had histological proof of recurrent carcinoma, except for one with an inaccessible site (retropharyngeal region), and the diagnosis was made by imaging. Detailed patient characteristics are shown in Table 1.

During the primary treatment course, $53 \%$ of patients received concurrent chemotherapy (mostly cisplatin-

Table 1. Patient and disease characteristics according to type of local relapse.*

\begin{tabular}{|c|c|c|}
\hline & $\begin{array}{l}\text { Residual } \\
\text { disease } \\
(n=34)\end{array}$ & $\begin{array}{l}\text { Recurrent } \\
\text { disease } \\
(n=15)\end{array}$ \\
\hline \multicolumn{3}{|l|}{ Sex } \\
\hline Male & $28(82.4 \%)$ & $10(66.7 \%)$ \\
\hline Female & $6(17.6 \%)$ & $5(33.3 \%)$ \\
\hline Age at presentation (years) & $55.5(33-84)$ & $49(29-72)$ \\
\hline \multicolumn{3}{|l|}{ WHO histologic type } \\
\hline 1 & $1(2.9 \%)$ & 0 \\
\hline$\|$ & $2(5.9 \%)$ & 0 \\
\hline III & $31(91.2 \%)$ & $15(100 \%)$ \\
\hline \multicolumn{3}{|l|}{ Primary $T$ stage $^{\dagger}$} \\
\hline $\mathrm{T} 1$ & $5(14.7 \%)$ & $1(6.7 \%)$ \\
\hline T2 & $7(20.6 \%)$ & $8(53.3 \%)$ \\
\hline T3 & $18(52.9 \%)$ & 5 (33.3\%) \\
\hline T4 & $4(11.8 \%)$ & $1(6.7 \%)$ \\
\hline \multicolumn{3}{|l|}{ Primary N stage ${ }^{\dagger}$} \\
\hline NO & $11(32.4 \%)$ & 5 (33.3\%) \\
\hline N1 & $16(47.1 \%)$ & $3(20 \%)$ \\
\hline N2 & $5(14.7 \%)$ & $6(40 \%)$ \\
\hline N3 & $2(5.9 \%)$ & $1(6.7 \%)$ \\
\hline \multicolumn{3}{|l|}{ Recurrent $\mathrm{T}$ stage ${ }^{\dagger \ddagger}$} \\
\hline rT1 & & $6(40 \%)$ \\
\hline rT2 & & $1(6.7 \%)$ \\
\hline rT3 & & $8(53.3 \%)$ \\
\hline rT4 & & 0 \\
\hline \multicolumn{3}{|l|}{ Recurrent N stage ${ }^{\dagger \ddagger}$} \\
\hline rNO & & $10(66.7 \%)$ \\
\hline rN1 & & $3(20 \%)$ \\
\hline rN2 & & $2(13.3 \%)$ \\
\hline rN3 & & 0 \\
\hline $\begin{array}{l}\text { Time from completion of primary } \\
\text { treatment to recurrence (days) }^{\dagger}\end{array}$ & & $654(217-1954)$ \\
\hline
\end{tabular}

Abbreviation: $\mathrm{WHO}=$ World Health Organization.

* Data are shown as No. (\%) of patients or median (range).

† Staging according to Union for International Cancer Control TNM classification 7th edition.

‡ Applicable only to patients with recurrent disease. 
based), with a median cumulative cisplatin dose of $160 \mathrm{mg} / \mathrm{m}^{2}$ (range, $100-300 \mathrm{mg} / \mathrm{m}^{2}$ ); $12 \%$ of patients received adjuvant chemotherapy with cisplatin and 5-fluorouracil (PF), while $10 \%$ of patients received induction chemotherapy (PF). Table 2 summarises the details of the primary treatment courses.

For residual disease, the median prescribed FSRT dose was 18 Gy (range, 12-18 Gy), delivered in a median of three fractions (range, 2-3 fractions), with a median fractional dose of 6 Gy (range, 5-6 Gy). The median $\mathrm{BED}_{10}$ was $28.8 \mathrm{~Gy}_{10}$ (range, 19.2-28.8 $\mathrm{Gy}_{10}$ ) and that of EQD2 was 24 Gy (range, 16-24 Gy). For recurrent disease, when FSRT was used alone, the median prescribed dose was 48 Gy (range, 14-48 Gy), delivered in a median of 6 fractions (range, 2-6 fractions), with a median fractional dose of $8 \mathrm{~Gy}$ (range, 6-8 Gy). In two patients, FSRT was used as a tumour boost on top of a long conventional fractionated reirradiation IMRT of 50 to $60 \mathrm{~Gy}$. The median $\mathrm{BED}_{10}$ was $86.4 \mathrm{~Gy}_{10}$ (range, 48-120 $\mathrm{Gy}_{10}$ ) and that of EQD2 was 72 Gy (range, 40-100 Gy). Figure 1 illustrates details of the setup and planning of FSRT. Table 3 summarises the FSRT

Table 2. Characteristics of primary treatment course. ${ }^{*}$

\begin{tabular}{lcc}
\hline & $\begin{array}{c}\text { Residual } \\
\text { disease } \\
(\mathrm{n}=34)\end{array}$ & $\begin{array}{c}\text { Recurrent } \\
\text { disease } \\
(\mathrm{n}=15)\end{array}$ \\
\hline Technique & $33(97.1 \%)$ & $11(73.3 \%)$ \\
IMRT & 0 & $3(20 \%)$ \\
2D conventional RT & $1(2.9 \%)$ & $1(6.7 \%)$ \\
Unknown & & \\
Dose to gross tumour/ & & \\
lymphadenopathy (Gy) & $33(97.1 \%)$ & $11(73.3 \%)$ \\
70 & $1(2.9 \%)$ & 0 \\
72 & 0 & $4(26.7 \%)$ \\
66 & & \\
No. of fractions & $20(58.8 \%)$ & $8(53.3 \%)$ \\
33 & $13(38.2 \%)$ & $7(46.7 \%)$ \\
35 & $1(2.9 \%)$ & 0 \\
36 & $92(62-168)$ & $97(57-169)$ \\
Time from pathological diagnosis & & \\
to completion of RT (days) & & $7(46.7 \%)$ \\
Concurrent chemotherapy & $14(41.2 \%)$ & 0 \\
Cisplatin 40 mg/m² weekly & $3(8.8 \%)$ & 0 \\
Cisplatin 100 mg/m² q3wks & $2(5.9 \%)$ & $8(53.3 \%)$ \\
Carboplatin & $15(44.1 \%)$ & \\
None & $160(100-300)$ & $200(160-240)$ \\
Concurrent cumulative cisplatin & & \\
dose (mg/m²) & $4(11.8 \%)$ & $1(6.7 \%)$ \\
Use of induction chemotherapy & $5(14.7 \%)$ & $1(6.7 \%)$ \\
Use of adjuvant chemotherapy & & \\
\hline
\end{tabular}

Abbreviations: 2D = two-dimensional; IMRT = intensity-modulated radiation therapy; q3wks = every 3 weeks; $\mathrm{RT}=$ radiotherapy.

* Data are shown as No. (\%) of patients or median (range). treatment parameters.

\section{Response and Local Control Rates}

The pathological complete response rate was $82.3 \%$ for the residual disease group. For the recurrent disease group, $93.3 \%$ achieved radiological shrinkage, with pathological complete response achieved in $60 \%$. The actuarial 3-year local control rates were $78.9 \%$ and $68.2 \%$ for the residual and recurrent disease groups, respectively. Overall, for the eight patients who failed to achieve local control after FSRT, five had successful salvage surgery, one developed bone metastases, one had extensive inoperable neck failure, and one relapsed locally again 1 year after reirradiation with disease too advanced for further salvage.

\section{Survival Outcomes}

For the residual disease group, the median PFS was 66.1 months, median OS was 102.0 months, and median DSS was not reached with our length of follow-up. Similar to local control rates, the recurrent disease group had inferior outcome, with median PFS of 29.3 months, median OS of 33.2 months, and median DSS of 40.9 months.

The actuarial 3-year PFS, DSS, and OS for the residual disease group were $66.2 \%, 82.2 \%$, and $74.0 \%$, respectively. For the recurrent disease group, the PFS, DSS, and OS were $40.0 \%, 58.7 \%$, and $46.7 \%$, respectively. Upon log-rank testing, the residual disease group had superior survival outcome after FSRT compared with the recurrent disease group, and the difference was statistically significant across all three endpoints (Figure 2).

\section{Prognostic Factors}

The cut-off values of FSRT GTV as a predictor for survival outcomes of the residual and recurrent disease groups were found to be $16 \mathrm{~mL}$ and $10 \mathrm{~mL}$, respectively.

FSRT GTVs of $\leq 16 \mathrm{~mL}$ for the residual disease group, and that of $\leq 10 \mathrm{~mL}$ for the recurrent disease group were associated with longer PFS and OS (Figure 3). N3 nodal staging status was associated with poorer PFS in the residual disease group. Other factors, including advanced initial $\mathrm{T}$ stage (T3-4 vs. T1-2) in patients in the residual disease group, and recurrent $\mathrm{T}$ stage (rT3-4 vs. rT1-2) in patients in the recurrent disease group showed only trends to inferior outcome in PFS or OS but were not statistically significant prognostic factors (Table 4). 


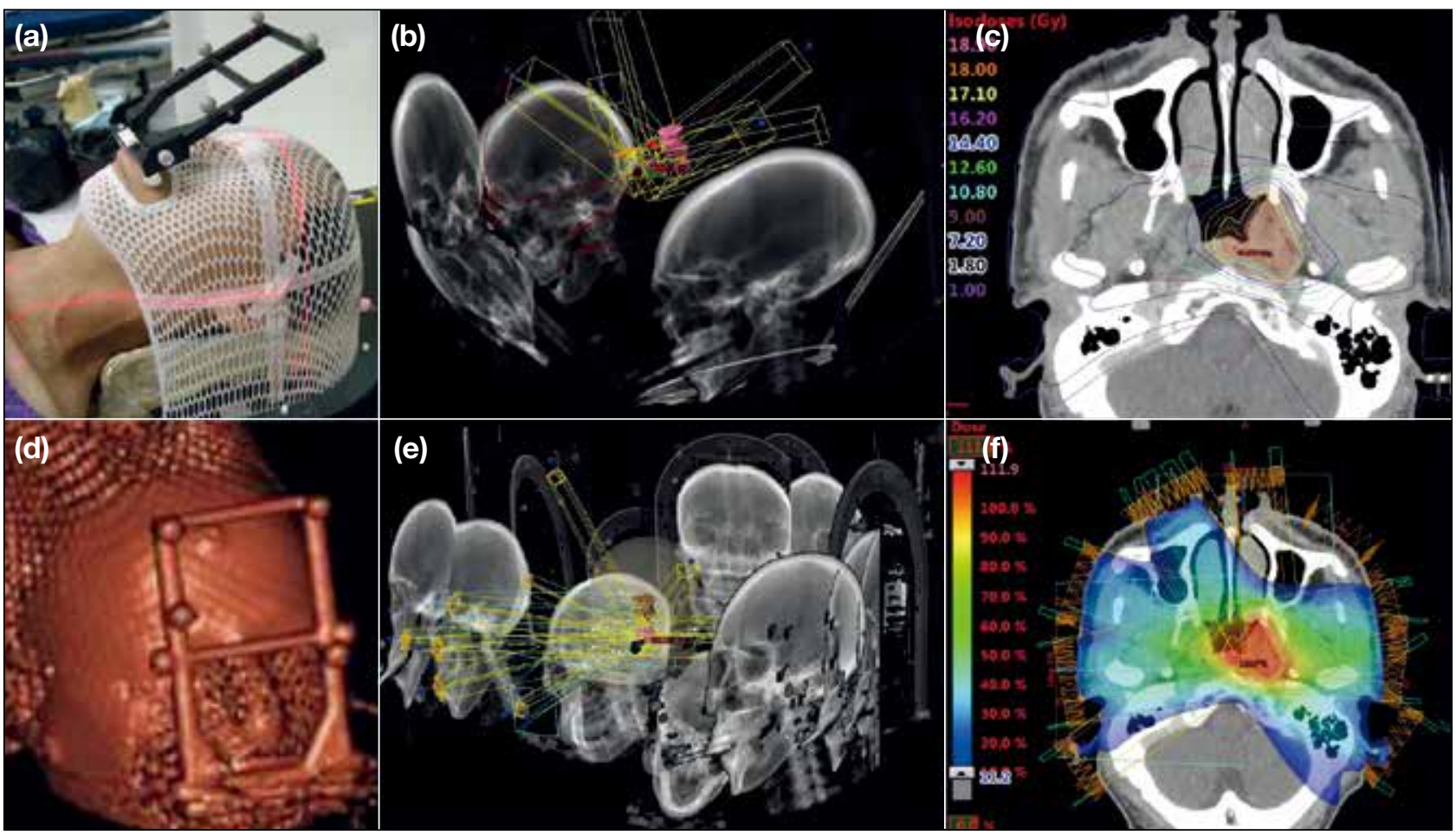

Figure 1. (a) Patient immobilised in tailor-made precision thermoplastic cast (Orfit [Wijnegem, Belgium]); (b) Zmed (Holliston [MA], United States) frameless stereotactic localisation system, which utilises a bite tray with reflective fiducial arrays plus a ceiling-mounted threedimensional infrared camera for optical localisation and tracking; (c) field designs of a multileaf collimation (MLC)-based fractionated stereotactic radiotherapy (FSRT) treatment (all except one of our patients received MLC-based treatment); (d) field designs of a cone-based FSRT treatment; (e, f) dose distributions of an MLC-based FSRT plan for a patient with persistent disease in the left nasopharynx. The 18-Gy $(100 \%)$ isodose line (orange) covered the planning target volume (yellow) well and the brainstem received a maximum of only 1 Gy in this reirradiation course.

Table 3. Treatment parameters of reirradiation fractionated stereotactic radiotherapy course. *

\begin{tabular}{|c|c|c|}
\hline & $\begin{array}{l}\text { Residual disease } \\
\quad(n=34)\end{array}$ & $\begin{array}{l}\text { Recurrent disease } \\
\qquad(n=15)\end{array}$ \\
\hline \multicolumn{3}{|l|}{ Technique } \\
\hline SRT alone & 34 (100\%) & 13 (86.7\%) \\
\hline $\mathrm{SRT}+\mathrm{IMRT}$ & 0 & $2(13.3 \%)$ \\
\hline \multicolumn{3}{|l|}{ MLC- or cone-based } \\
\hline MLC & 33 (97.1\%) & 15 (100\%) \\
\hline Cone & $1(2.9 \%)$ & 0 \\
\hline GTV $(\mathrm{mL})$ & $12.8(4.6-66.8)$ & $15.9(2.1-74.9)$ \\
\hline Total prescribed dose (Gy) & $18(12-18)$ & $48(14-48)$ \\
\hline Fractional dose (Gy) & $6(5-6)$ & $8(6-8)$ \\
\hline No. of fractions & $3(2-3)$ & $6(2-6)$ \\
\hline \multicolumn{3}{|l|}{ Time/dose/fractionation } \\
\hline 18 Gy in 3 fr, 2 fr per week & $31(91.2 \%)$ & 0 \\
\hline 12 Gy in 2 fr, 2 fr per week & $2(5.9 \%)$ & 0 \\
\hline 15 Gy in $3 \mathrm{fr}, 2$ fr per week & $1(2.9 \%)$ & 0 \\
\hline 48 Gy in $6 \mathrm{fr}, 2 \mathrm{fr}$ per week & 0 & $11(73.3 \%)$ \\
\hline 30 Gy in 5 fr, 2 fr per week & 0 & $1(6.7 \%)$ \\
\hline IMRT 50 Gy/25 fr + SRT tumour boost 14 Gy/2 fr & 0 & $1(6.7 \%)$ \\
\hline IMRT $60 \mathrm{~Gy} / 30 \mathrm{fr}+\mathrm{SRT}$ boost $30 \mathrm{~Gy} / 5 \mathrm{fr}$ & 0 & $1(6.7 \%)$ \\
\hline SRT 32 Gy/4 fr then $15 \mathrm{~Gy} / 3 \mathrm{fr}$ & 0 & $1(6.7 \%)$ \\
\hline Biologically effective dose with $\alpha / \beta=10$ Gy $\left(G_{10}\right)$ & $28.8(19.2-28.8)$ & $86.4(48-120)$ \\
\hline Equivalent total dose in 2-Gy fr (Gy) & $24(16-24)$ & $72(40-100)$ \\
\hline
\end{tabular}

Abbreviations: $\mathrm{fr}$ = fraction; GTV = gross tumour volume; IMRT = intensity-modulated radiation therapy; MLC = multileaf collimation; $\mathrm{SRT}=$ stereotactic radiotherapy.

* Data are shown as No. (\%) of patients or median (range). 


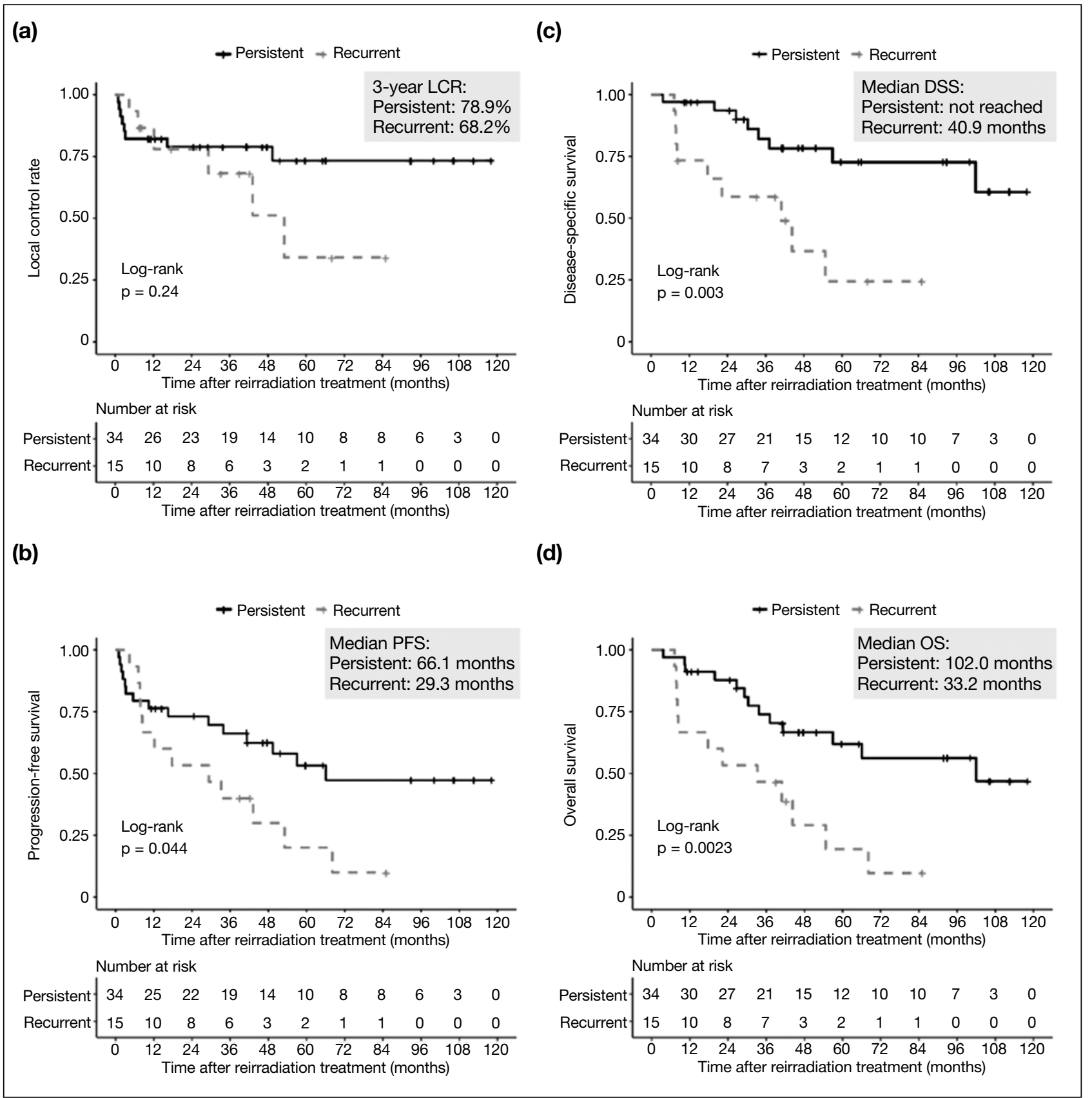

Figure 2. Kaplan-Meier curves and 3-year actuarial rates by type of local failure. Log-rank tests were performed to test for statistical differences: (a) local control rate (LCR); (b) progression-free survival (PFS); (c) disease-specific survival (DSS); and (d) overall survival (OS).

\section{Complications}

All patients were able to complete the scheduled FSRT. No significant acute complications occurred. Thirteen severe late complications occurred in 12 patients $(24 \%)$ after FSRT. The incidence of severe late complications was higher in the recurrent disease group (in 6 patients, $40 \%$ ) than in the residual disease group (18\%).

Overall, five patients (10\%) developed massive haemorrhage and all died of this event. Among them, two had unsalvageable locoregional disease and the haemorrhage could have been due to disease progression. All of these haemorrhagic events happened within 5 years of primary RT, and within 3 years of reirradiation FSRT. Other known severe late complications associated with reirradiation, including temporal lobe necrosis, cranial nerve palsy, mandible/maxilla radionecrosis, and local mucosal necrosis all occurred at a rate of $<5 \%$. One patient 


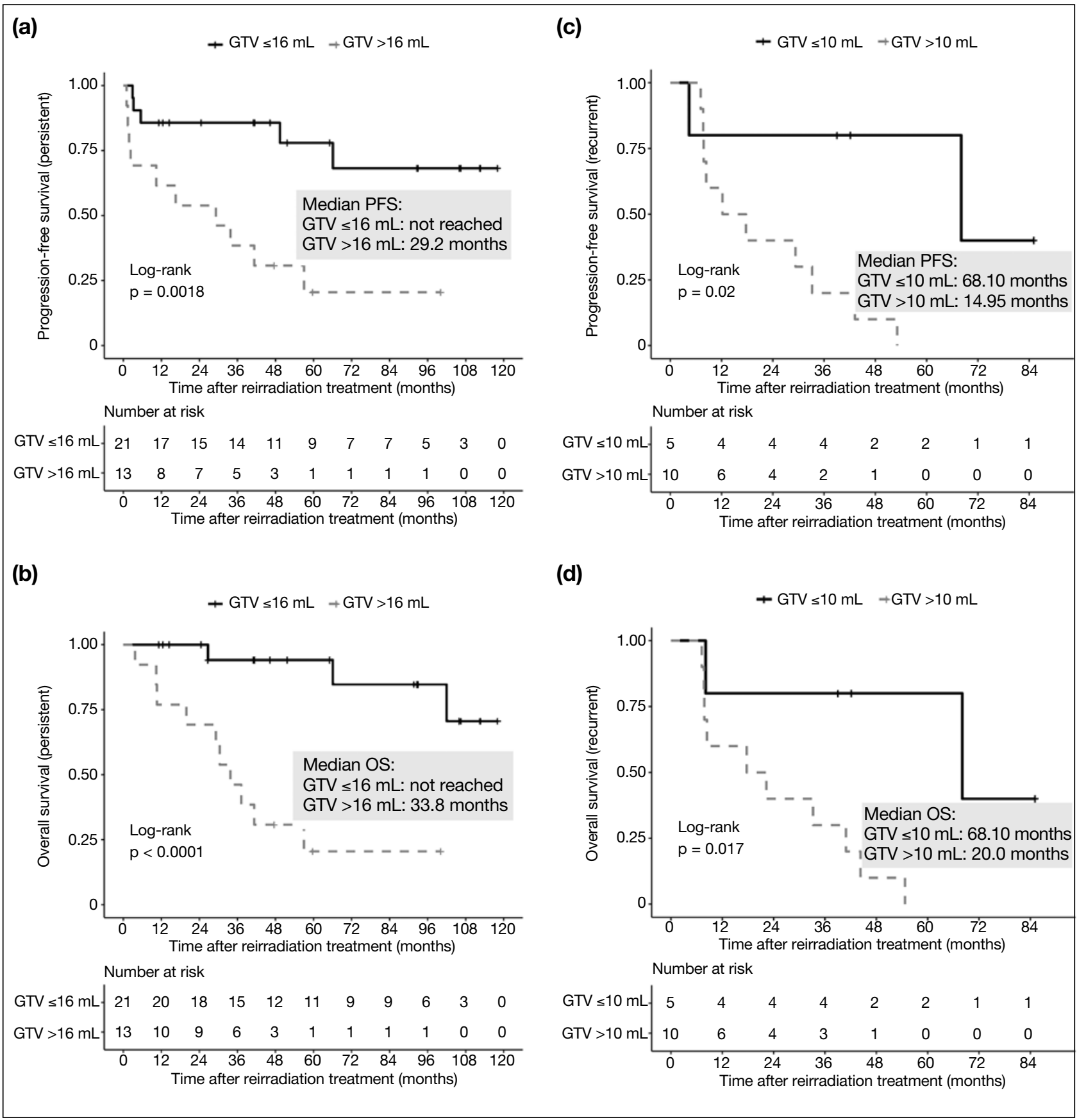

Figure 3. (a) Progression-free survival and (b) overall survival of persistent (residual) disease group stratified by gross tumour volume with a cut-off of $16 \mathrm{~mL}$. (c) Progression-free survival and (d) overall survival of recurrent disease group stratified by gross tumour volume with a cut-off of $10 \mathrm{~mL}$.

who had undergone a salvage nasopharyngectomy with the maxillary swing approach after failing local control with FSRT developed $\mathrm{C} 1 / 2$ osteomyelitis complicated by an epidural abscess and meningitis 2 years later but survived the event. Details of severe toxicities are shown in Table 5.

\section{DISCUSSION}

Treatment options for NPC with local failure can be operative or non-operative. Important distinctions exist between residual and recurrent disease, with better survival and disease control rates for those with residual disease. This finding is consistent across multiple 
TTS Lau, LL Chan, ELM Yu, et al

Table 4. Association with overall survival and progression-free survival for residual disease group and recurrent disease group.

\begin{tabular}{|c|c|c|c|c|}
\hline \multirow[t]{2}{*}{ Residual disease } & \multicolumn{2}{|c|}{ Overall survival } & \multicolumn{2}{|c|}{ Progression-free survival } \\
\hline & $\mathrm{HR}_{\text {unadj }}(95 \% \mathrm{Cl})$ & $\mathrm{p}$ Value & $\mathrm{HR}_{\text {unadj }}(95 \% \mathrm{Cl})$ & $\mathrm{p}$ Value \\
\hline Age & $1.03(0.98-1.08)$ & 0.214 & $1.02(0.98-1.07)$ & 0.368 \\
\hline Female sex & $1.44(0.44-4.72)$ & 0.544 & $2.56(0.87-7.51)$ & 0.087 \\
\hline MRI T3/4 (ref T1/2)* & $1.30(0.39-4.27)$ & 0.670 & $1.04(0.35-3.09)$ & 0.940 \\
\hline MRI N3 (ref NO/1/2) $)^{*}$ & $5.38(0.59-48.8)$ & 0.135 & $5.13(1.03-25.6)$ & 0.046 \\
\hline GTV >16 mL & $12.84(2.69-61.2)$ & 0.001 & $4.87(1.63-14.5)$ & 0.005 \\
\hline $\mathrm{BED}_{10}\left(\mathrm{~Gy}_{10}\right)$ & $1.06(0.85-1.33)$ & 0.605 & $1.08(0.87-1.35)$ & 0.486 \\
\hline \multirow[t]{2}{*}{ Recurrent disease } & \multicolumn{2}{|c|}{ Overall survival } & \multicolumn{2}{|c|}{ Progression-free survival } \\
\hline & $\mathrm{HR}_{\text {unadi }}(95 \% \mathrm{Cl})$ & $\mathrm{p}$ Value & $\mathrm{HR}_{\text {unadi }}(95 \% \mathrm{Cl})$ & $p$ Value \\
\hline Age & $1.03(0.97-1.09)$ & 0.335 & $1.03(0.97-1.09)$ & 0.330 \\
\hline Female sex & $0.29(0.06-1.38)$ & 0.119 & $0.27(0.06-1.30)$ & 0.103 \\
\hline MRI T3/4 (ref T1/2)* & $2.18(0.69-6.91)$ & 0.184 & $2.46(0.77-7.84)$ & 0.128 \\
\hline MRI N3 $(\operatorname{ref} \mathrm{NO} / 1 / 2)^{\star}$ & $6.48(0.59-71.6)$ & 0.127 & $4.14(0.43-39.9)$ & 0.219 \\
\hline GTV $>10 \mathrm{~mL}$ & $8.41(1.06-66.8)$ & 0.044 & $8.16(1.02-65.3)$ & 0.048 \\
\hline $\mathrm{BED}_{10}\left(\mathrm{~Gy}_{10}\right)$ & $1.00(0.96-1.05)$ & 0.832 & $1.00(0.96-1.04)$ & 0.940 \\
\hline Cumulative cisplatin dose & $1.01(0.98-1.03)$ & 0.718 & $1.01(0.98-1.03)$ & 0.622 \\
\hline Recurrent T3/4 (ref T1/2) & $3.13(0.82-11.9)$ & 0.094 & $3.54(0.93-13.5)$ & 0.065 \\
\hline
\end{tabular}

Abbreviations: $95 \% \mathrm{Cl}=95 \%$ confidence interval; $\mathrm{BED}_{10}=$ biologically effective dose with $\alpha / \beta=10 \mathrm{~Gy}$; GTV = gross tumour volume; $\mathrm{HR}_{\text {unadj }}=$ unadjusted hazard ratios; $\mathrm{MRI}=$ magnetic resonance imaging.

${ }^{*} \mathrm{MRl}$ staging at first presentation.

Table 5. Severe late toxicities attributable to reirradiation.

\begin{tabular}{lll}
\hline & $\begin{array}{c}\text { Residual } \\
\text { disease } \\
(\mathrm{n}=34)\end{array}$ & $\begin{array}{c}\text { Recurrent } \\
\text { disease } \\
(\mathrm{n}=15)\end{array}$ \\
\hline Fatal haemorrhage & $1(3 \%)$ & $4(27 \%)$ \\
Temporal lobe necrosis & $2(6 \%)$ & 0 \\
Mandible/maxilla radionecrosis & $1(3 \%)$ & $1(7 \%)$ \\
Local mucosal necrosis & $1(3 \%)$ & 0 \\
Cranial nerve palsy & 0 & $2(13 \%)$ \\
C1/2 osteomyelitis complicated & $1(3 \%)$ & 0 \\
with epidural abscess, meningitis & & \\
Total & $6(18 \%)$ & $7(47 \%)^{\star}$ \\
\hline
\end{tabular}

Abbreviation: $\mathrm{C} 1 / 2$ = cervical spine level 1 and 2 .

* Developed in 6 patients.

studies in the literature. It remains unclear whether there is a relationship between tumour biology and poorer reirradiation response of recurrent disease, i.e., revival of cancer cells, compared with residual disease, which could be due to marginal miss of boost dose, or prolonged/ incomplete regression. In our study, although patients with residual and recurrent disease were treated with a similar salvage RT technique, the radiation doses they received were vastly different, and they were mostly analysed as two distinctive groups.

For residual disease, in particular for early-stage disease (rT1-2), treatment results and survival rates were highly favourable and comparable to patients who had had a complete response after the first treatment course. Various salvage options including surgery, further radiation boost by external beam RT or brachytherapy, or photodynamic therapy all result in good and comparable response rates. ${ }^{3,14-24}$ Recurrent disease, however, is associated with issues of radioresistance and higher morbidity with irradiation, thus surgery is often preferred when it is technically feasible. A matched cohort analysis showed that salvage endoscopic nasopharyngectomy might be superior to IMRT in terms of survival outcome, qualityof-life benefits, and complication rates for selected rT1-T3 NPC. ${ }^{25}$ Nonetheless, there has been no direct prospective comparison between different techniques of nasopharyngectomy with various non-operative approaches, and such trials would not be feasible in a randomised, well-stratified manner without largescale multi-centre cooperation and stringent quality control. Besides, it is important to recognise that each approach has its unique advantages and shortcomings and the treatment decision has to take multiple factors into account, such as the location and extent of disease, availability of modality and expertise, patient preference, and co-morbidities. Table 6 summarises the characteristics of different treatment approaches in salvage treatment of NPC..$^{3,14-24}$

Our study provides updated data on the efficacy of LINAC-based FSRT, using a frameless stereotactic system and IMRT technique, in treating patients with 
Table 6. Overview of different treatment approaches in salvage treatment of nasopharyngeal carcinoma.

\begin{tabular}{|c|c|c|}
\hline Modalities & Characteristics & Complications of note \\
\hline $\begin{array}{l}\text { Nasopharyngectomy }{ }^{15,16} \\
\text { - Open } \\
\text { - Endoscopic } \\
\text { - Robotic-assisted }\end{array}$ & $\begin{array}{l}\text { - Highly specialised surgery, required expertise due to complex } \\
\text { anatomy } \\
\text { - Surgery can only be curative if the tumour is radically removed, } \\
\text { thus feasible only for rT1-2 to limited rT3 disease, and also no } \\
\text { carotid artery involvement } \\
\text { - No concern on radioresistance } \\
\text { - Endoscopic/robotic-assisted technique: minimally invasive, } \\
\text { good visualisation but had to overcome the issues of limited } \\
\text { instrumentation space } \\
\text { - If positive margin resection, may consider postoperative RT or } \\
\text { chemotherapy }\end{array}$ & $\begin{array}{l}\text { More reported with open approaches: } \\
\text { - Palatal defect, osteonecrosis, flap } \\
\text { - } \text { necrosis } \\
\text { - Facial scarring, trismus } \\
\text { - Dysphagia, aspiration } \\
\text { - Carotid bleeding }\end{array}$ \\
\hline $\begin{array}{l}\text { External beam RT } \\
\text { - SRS } \\
\text { - } \text { FSRT } \\
\text { - } \text { IMRT }^{3,14,17-19}\end{array}$ & $\begin{array}{l}\text { - Non-invasive } \\
\text { - High-precision RT techniques are preferred, so to allow a rapid } \\
\text { dose fall-off from tumour targets to normal at-risk organs in } \\
\text { proximity } \\
\text { - Flexible strategies allow treatment for advanced recurrence: } \\
\text { IMRT could deliver different dose levels to avoid surrounding } \\
\text { vital structures; SRS, FSRT could be used as boost dose }\end{array}$ & $\begin{array}{l}\text { Associated with reirradiation: } \\
\text { - Neurological: radiation myelitis, } \\
\text { temporal lobe necrosis, cranial nerve } \\
\text { palsies } \\
\text { - Carotid pseudoaneurysm } \\
\text { - Soft tissue and bone necrosis } \\
\text { - Radiation osteomyelitis (skull base, }\end{array}$ \\
\hline $\begin{array}{l}\text { Brachytherapy20-23 } \\
\text { - Intracavitary: iridium (Ir-192) } \\
\text { after loading } \\
\text { - Interstitial: gold (Au-198) } \\
\text { grain implant }\end{array}$ & $\begin{array}{l}\text { - Delivers high radiation dose to targets with a rapid dose fall-off } \\
\text { to preserve surrounding normal tissues } \\
\text { - Due to short range, only recommended for persistent/ } \\
\text { recurrent T1 disease in current practice } \\
\text { - Interstitial - some locations, e.g., cartilage of the Eustachian } \\
\text { tube crus are not assessable to the gun applicator } \\
\text { - Could be used as a dose boost }\end{array}$ & $\begin{array}{l}\text { cervical spine) } \\
\text { - Endocrine dysfunction }\end{array}$ \\
\hline Photodynamic therapy ${ }^{24}$ & $\begin{array}{l}\text { - Illuminate tumour with a non-thermic laser after IV injection of } \\
\text { photosensitiser } \\
\text { - Effective treatment depth with second-generation } \\
\text { photosensitisers (e.g., temoporfin) is } 10 \mathrm{~mm} \text { : recommended } \\
\text { for } T 1 / 2 \text { disease }<10 \mathrm{~mm} \text { depth (more data for residual } \\
\text { disease) } \\
\text { - No radiation toxicities. Treatment easy to deliver and } \\
\text { repeatable }\end{array}$ & $\begin{array}{l}\text { - Headache } \\
\text { - Photosensitivity } \\
\text { - Tinnitus, middle ear effusion }\end{array}$ \\
\hline
\end{tabular}

Abbreviations: FSRT = fractionated stereotactic radiotherapy; IMRT = intensity-modulated radiation therapy; IV = intravenous; $r T=$ Union for International Cancer Control TNM classification; RT = radiotherapy; SRS = stereotactic radiosurgery.

NPC with local failure after high-dose primary IMRT. The frameless system based on live tracking of fiducials was non-invasive, required no neurosurgical expertise, and improved patients' comfort compared with the conventional frame-based technique. Moreover, our study findings are highly relevant to contemporary practice as almost all of our patients received IMRT (now the standard of care in many countries) as their primary treatment. In fact, it has been proposed that with the prevailing use of IMRT, the nature of recurrences is likely to be different from those in patients in the older era of two-dimensional or three-dimensional conformal RT, when patients with NPC may have failed locally due to marginal misses or underdosing to the clinical targets. In the setting of modern imaging and RT techniques, local recurrence after high-dose RT may instead be accounted for by the presence of populations of radioresistant cancer cells that survive the initial course of treatment and may pose a new set of challenges for salvage. Therefore, previous results of salvage RT after conventional techniques may not be as readily applicable for patients treated in the IMRT era. ${ }^{14,26}$ From the overall results of our study, in spite of these differences, our clinical outcomes are comparable to previously reported FSRT studies in the literature (Table $7^{22,27-37}$ ).

On reviewing patients who suffered from fatal nasopharyngeal haemorrhage as a complication, all of these patients presented first with sentinel bleeds up to 2 months before their fatal episode, suggesting the possibility of earlier detection of carotid artery pseudoaneurysms by raising physicians' and patients' awareness, especially in patients with known risk factors such as reirradiation and skull base radionecrosis. ${ }^{38}$ Earlier detection may allow preventive endovascular interventions to be performed. 
TTS Lau, LL Chan, ELM Yu, et al

Table 7. Literature review of stereotactic reirradiation studies for nasopharyngeal carcinoma (only included studies with retrievable full text via PubMed or journal webpages).

\begin{tabular}{|c|c|c|c|c|c|}
\hline First author & No. of cases & $\begin{array}{l}\text { Reirradiation technique and } \\
\text { dose (Gy) }\end{array}$ & Local control* $^{\star}$ & Survival $^{*}$ & Major complications \\
\hline $\begin{array}{l}\text { Orecchia, } \\
1999^{30}\end{array}$ & $\mathrm{R}: 13$ (rT1-4) & FSRT 24 Gy in 2-4 fr & $\begin{array}{l}\text { Radiological CR } \\
38 \%\end{array}$ & $3-y$ OS 31\% & Nil \\
\hline Ahn, $2000^{31}$ & $\begin{array}{l}\text { R: } 12 \text { (no } \\
\text { staging info) }\end{array}$ & FSRT 45-65 Gy, 2.5-3 Gy/fr & 2 у $92 \%$ & 2 -y OS 60\% & Nil \\
\hline Xiao, $2001^{32}$ & $\begin{array}{l}P: 32 \\
R: 18(r T 1-4)\end{array}$ & $\begin{array}{l}\text { FSRT 14-35 Gy, 6-8, 12, or } \\
15 \text { Gy/fr, } \pm \text { external beam RT }\end{array}$ & Not reported & $\begin{array}{l}\text { 3-y OS 60\% } \\
\text { 3-y DFS 74\% }\end{array}$ & $\mathrm{FH} 16 \%$ \\
\hline Pai, $2002^{33}$ & R: 36 (rT1-4) & $\begin{array}{l}\text { 3DCRT 20-60 Gy + } \\
\text { SRS 8-20 Gy }\end{array}$ & 3 у $56 \%$ & $3-y$ OS $54 \%$ & LMN 11\% \\
\hline Chua, $2003^{34}$ & $\begin{array}{l}P: 7 \\
R: 11(r T 1-2)\end{array}$ & SRS 11-14 Gy & 2 y $72 \%$ & $\begin{array}{l}\text { 2-y OS } 86 \% \\
\text { P: 2-y LFFS 100\% } \\
\text { R: 2-y LFFS 55\% }\end{array}$ & TLN 6\% \\
\hline Chua, $2005^{35}$ & $\mathrm{R}: 31$ (rT1-4) & $\begin{array}{l}\text { IMRT } 50-60 \text { Gy in } 25-30 \mathrm{fr} \\
\pm \text { SRS } 8.5-12.6 \text { Gy boost in } \\
\text { around } 1 / 3 \text { of patients (who } \\
\text { had rT3-4 disease with } D_{\min } \text { of } \\
\text { PTV < } 45 \text { Gy) }\end{array}$ & 1 y $56 \%$ & $1-y$ OS 63\% & $\begin{array}{l}\text { CNP (10\%), brain necrosis } \\
\text { ( } 7 \%) \text {, soft tissue fibrosis (3\%), } \\
\text { grade } \geq 3 \text { ototoxicity }(10 \%)\end{array}$ \\
\hline Low, $2006^{22}$ & $\begin{array}{l}\text { P: } 5 \\
\text { R: } 31 \text { (rT1-2) }\end{array}$ & SRS 18 Gy + BT 12 Gy in 2 fr & $\begin{array}{l}\text { P: } 5 \text { y } 100 \% \\
\text { R: } 5 \text { y } 57 \%\end{array}$ & $\begin{array}{l}\text { P: } 5 \text {-y OS } 100 \% \\
\text { R: } 5 \text {-y OS } 53 \%\end{array}$ & $\begin{array}{l}\text { CNP 20\%, TLN 8\%, skull base } \\
\text { osteonecrosis (17\%), palatal } \\
\text { fibrosis (17\%), trismus (20\%) }\end{array}$ \\
\hline $\mathrm{Wu}, 2007^{27}$ & $\begin{array}{l}P: 34 \\
R: 56(r T 1-4)\end{array}$ & $\begin{array}{l}\text { P: FSRT 10-24 Gy in 2-4 fr } \\
\text { R: FSRT 12-49 Gy in 2-8 fr }\end{array}$ & $\begin{array}{l}\text { P: } 3 \text { y } 89 \% \\
\text { R: } 3 \text { y } 75 \%\end{array}$ & $\begin{array}{l}\text { P: 3-y DSS } 81 \% \\
\text { R: } 3-y \text { DSS } 46 \%\end{array}$ & $\begin{array}{l}\text { FH ( } 2 \%), \text { TLN ( } 7 \%) \text {, brainstem } \\
\text { necrosis (3\%), LMN (7\%) }\end{array}$ \\
\hline Seo, $2009^{28}$ & R: 35 (rT1-4) & FSRT 24-45 Gy in 3-5 fr & LFFS reported & $\begin{array}{l}\text { 5-y OS 60\% } \\
5 \text {-y LFFS 79\% }\end{array}$ & FH (6\%), LMN (6\%) \\
\hline Ozyigit, $2011^{29}$ & $\mathrm{R}: 24$ (rT1-4) & FSRT 30 Gy in $5 \mathrm{fr}$ & 2 y $82 \%$ & $2-y$ CSS 64\% & $\begin{array}{l}\text { Carotid blowout syndrome } \\
(17 \%), \text { CNP (12\%), brain } \\
\text { necrosis }(4 \%)\end{array}$ \\
\hline Liu, $2013^{36}$ & $P: 136$ & FSRT 8-32 Gy in 2-8 fr & LFFS reported & $\begin{array}{l}3-y \text { LFFS 95\% } \\
5-y \text { OS 76\% }\end{array}$ & $\begin{array}{l}\text { FNH (3.7\%), CNP (6\%), TLN } \\
(4.4 \%)\end{array}$ \\
\hline $\begin{array}{l}\text { Dizman, } \\
2014^{37}\end{array}$ & $\mathrm{R}: 24$ (rT1-4) & FSRT 25-30 Gy in 5 fr & 3 y $21 \%$ & $3-y$ OS 31\% & $\begin{array}{l}\text { Grade } 4 \text { acute mucositis (4\%), } \\
\text { TLN (4\%) }\end{array}$ \\
\hline Current & $\begin{array}{l}P: 34 \\
R: 15 \text { (rT1-3) }\end{array}$ & $\begin{array}{l}\text { P: FSRT } 12-18 \text { Gy in } 2-3 \mathrm{fr} \\
\text { R: FSRT } 14-48 \text { Gy in 2-6 fr }\end{array}$ & $\begin{array}{l}P: 3 \text { y } 79 \% \\
\text { R: } 3 \text { y } 68 \%\end{array}$ & $\begin{array}{l}\text { P: } 3-y \text { DSS } 82 \%, \\
3-y \text { OS } 74 \% \\
\text { R: } 3-y \text { DSS } 59 \%, \\
\text { 3-y OS } 47 \% \\
\end{array}$ & $\begin{array}{l}\text { FH (10\%), CNP (4\%), TLN } \\
(4 \%), \text { LMN (2\%), osteonecrosis } \\
(4 \%) \text {, osteomyelitis ( } 2 \%)\end{array}$ \\
\hline
\end{tabular}

Abbreviations: $3 \mathrm{DCRT}=$ three-dimensional conformal radiotherapy; $\mathrm{BT}=$ brachytherapy; $\mathrm{CNP}=$ cranial nerve palsy; $\mathrm{CR}=$ complete response; CSS = cancer-specific survival; $D_{\min }$ of PTV = minimum dose received by planning target volume; DFS = disease-free survival; DSS = disease-specific survival; $F H$ = fatal haemorrhage; $F N H$ fatal nasopharyngeal haemorrhage; $f r=$ fraction; FSRT = fractionated stereotactic radiotherapy; IMRT = intensity-modulated radiation therapy; LFFS = local failure-free survival; LMN = lower motor neuron; NPC = nasopharyngeal carcinoma; OS = overall survival; P = persistent NPC; R = recurrent NPC; rT = Union for International Cancer Control TNM classification; RT = radiotherapy; SRS = stereotactic radiosurgery; TLN = temporal lobe necrosis.

* Percentage values rounded up to the nearest whole number.

As our study only included a limited number of patients and survival events, conclusions regarding prognostic factors should be drawn with caution, given the known limitations of variable analyses of small cohorts. Nonetheless, in the residual disease group, we found an impact of FSRT GTV with a cut-off of $16 \mathrm{~mL}$ on OS and PFS, similar to findings reported in many previous studies..$^{27,39-41}$ The cut-off values of this GTV in relation to survival outcomes for the residual and recurrent disease groups identified by receiver operating characteristic analysis were different $(16 \mathrm{~mL}$ and $10 \mathrm{~mL}$, respectively). We postulate that this difference could be due to the inherently poorer radiosensitivity of recurrent disease.
For the recurrent disease group, given the very limited number of patients in the cohort, variable analysis was more underpowered and might explain why some commonly reported important prognostic factors such as rT stage ${ }^{28,29}$ failed to reach statistical significance, and the significance value of GTV was just below 0.05 $(p=0.044$ for OS, $p=0.048$ for PFS). However, on careful assessment of all the regression analysis results, the hazard ratios and $p$ values of FSRT GTV far outweigh those of either initial or recurrent $\mathrm{T}$ stage in both groups. Over the years, much effort has been made to formulate prognostic algorithms to predict radioresistance in recurrence, so that low-risk patients could be confidently 
treated with reirradiation, whereas the unfavourable high-risk group may be managed more aggressively or recruited into clinical trials. ${ }^{42,43}$ With the changing patient population and treatment advancements, the prognostic effects of different factors could be dynamic and should be continuously examined.

Looking to the future, the use of charged-particle RT, including intensity-modulated ion therapy (IMIT) and intensity-modulated proton therapy (IMPT), potentially offers physical and biologic advantages over photonbased IMRT. The multicentric in silico ROCOCO trial has demonstrated further reduced doses to OARs using IMIT or IMPT compared with photon therapy. ${ }^{44}$ Very recently, various group had been studying intensitymodulated carbon ion RT in clinical practice for salvage reirradiation of NPC, and has published promising early results. ${ }^{45,46}$ However, long-term follow-up is needed to assess the long-term outcome and late toxicities, and also the optimal dose and fractionation.

\section{CONCLUSION}

In summary, we have presented our findings on the efficacy and safety of LINAC-based FSRT, using a frameless stereotactic system and IMRT technique, in treating patients with NPC with local failure (including residual and recurrent disease) after high-dose primary IMRT. Using this less-invasive and resource-friendly technique, the clinical outcomes were comparable to those in the literature. FSRT GTV was identified as a predictor of PFS and OS in patients irradiated for residual disease. We look forward to more studies reporting outcomes of reirradiation for patients treated in the IMRT era, and also eagerly await long-term results from IMIT and IMPT, which may further raise the therapeutic ratio and overcome the existing barriers to reirradiation.

\section{REFERENCES}

1. Hong Kong Cancer Registry, Hospital Authority, Hong Kong SAR Government. 2018. Available from: https://www3.ha.org. hk/cancereg/. Accessed 10 Jan 2018.

2. Zhang B, Mo Z, Du W, Wong Y, Liu L, Wei Y. Intensity-modulated radiation therapy versus $2 \mathrm{D}-\mathrm{RT}$ or 3D-CRT for the treatment of nasopharyngeal carcinoma: A systematic review and meta-analysis. Oral Oncol. 2015;51:1041-6.

3. Chan OS, Sze HC, Lee MC, Chan LL, Chang AT, Lee SW. Reirradiation with intensity-modulated radiotherapy for locally recurrent T3 to T4 nasopharyngeal carcinoma. Head Neck. 2017;39:533-40.

4. Wu LR, Liu YT, Jiang N, Fan YX, Wen J, Huang SF, et al. Tenyear survival outcomes for patients with nasopharyngeal carcinoma receiving intensity-modulated radiotherapy: an analysis of 614 patients from a single center. Oral Oncol. 2017;69:26-32.

5. Au KH, Ngan RK, Ng AW, Poon DM, Ng WT, Yuen KT, et al.
Treatment outcomes of nasopharyngeal carcinoma in modern era after intensity modulated radiotherapy (IMRT) in Hong Kong: A report of 3328 patients (HKNPCSG 1301 study). Oral Oncol. 2018;77:16-21.

6. Suárez C, Rodrigo JP, Rinaldo A, Langendijk JA, Shaha AR, Ferlito A. Current treatment options for recurrent nasopharyngeal cancer. Eur Arch Otorhinolaryngol. 2010;267:1811-24.

7. Xu T, Tang J, Gu M, Liu L, Wei W, Yang H. Recurrent nasopharyngeal carcinoma: a clinical dilemma and challenge. Curr Oncol. 2013;20:e406-19.

8. Stoker SD, van Diessen JN, de Boer JP, Karakullukcu B, Leemans CR, Tan IB. Current treatment options for local residual nasopharyngeal carcinoma. Curr Treat Options Oncol. 2013;14:475-91.

9. Chua DT, Wu SX, Lee V, Tsang J. Comparison of single versus fractionated dose of stereotactic radiotherapy for salvaging local failures of nasopharyngeal carcinoma: a matched-cohort analysis . Head Neck Oncol. 2009;1:13.

10. Kwong DL, Nicholls J, Wei WI, Chua DT, Sham JS, Yuen PW, et al. The time course of histologic remission after treatment of patients with nasopharyngeal carcinoma. Cancer. 1999;85:1446-53.

11. Nieder C, Langendijk J, editors. Re-irradiation: New Frontiers Switzerland: Springer; 2017.

12. Wang HZ, Luo JW, Yi JL, Huang XD, Zhang SP, Wang K, et al The tolerance of brainstem in reirradiation with intensity modulated radiation therapy in recurrent nasopharyngeal carcinoma. Int $\mathbf{J}$ Radiat Oncol Biol Phys. 2016;96:E340.

13. Schultheiss TE. The radiation dose-response of the human spinal cord. Int J Radiat Oncol Biol Phys. 2008;71:1455-9.

14. Kong L, Wang L, Shen C, Hu C, Wang L, Lu JJ. Salvage intensity-modulated radiation therapy (IMRT) for locally recurrent nasopharyngeal cancer after definitive IMRT: a novel scenario of the modern era. Sci Rep. 2016;6:32883.

15. Tsang RK, Wei WI. Salvage surgery for nasopharyngeal cancer. World J Otorhinolaryngol Head Neck Surg. 2015;1:34-43.

16. Liu J, Yu H, Sun X, Wang D, Gu Y, Liu Q, et al. Salvage endoscopic nasopharyngectomy for local recurrent or residual nasopharyngeal carcinoma: a 10-year experience. Int J Clin Oncol. 2017;22:83442.

17. Lu TX, Mai WY, The BS, Zhao C, Han F, Huang Y, et al. Initial experience using intensity-modulated radiotherapy for recurrent nasopharyngeal carcinoma. Int J Radiat Oncol Biol Phys. 2004;58:682-7.

18. Roeder F, Zwicker F, Saleh-Ebrahimi L, Timke C, Thieke C, Bischof $\mathrm{M}$, et al. Intensity modulated or fractionated stereotactic reirradiation in patients with recurrent nasopharyngeal cancer. Radiat Oncol. 2011;6:22.

19. Qiu S, Lin S, Tham IW, Pan J, Lu J, Lu JJ. Intensity-modulated radiation therapy in the salvage of locally recurrent nasopharyngeal carcinoma. Int J Radiat Oncol Biol Phys. 2012;83:676-83.

20. Leung TW, Tung SY, Sze WK, Sze WM, Wong VY, O SK. Salvage brachytherapy for patients with locally persistent nasopharyngeal carcinoma. Int J Radiat Oncol Biol Phys. 2000;47:405-12.

21. Leung TW, Tung SY, Sze WK, Sze WM, Wong VY, Wong CS, et al. Salvage radiation therapy for locally recurrent nasopharyngeal carcinoma. Int J Radiat Oncol Biol Phys. 2000;48:1331-8.

22. Low JS, Chua ET, Gao F, Wee JT. Stereotactic radiosurgery plus intracavitary irradiation in the salvage of nasopharyngeal carcinoma. Head Neck. 2006;28:321-9.

23. Kwong DL, Wei WI, Cheng AC, Choy DT, Lo AT, Wu PM, et al. Long term results of radioactive gold grain implantation for the treatment of persistent and recurrent nasopharyngeal carcinoma. Cancer. 2001;91:1105-13. 
24. Wildeman MA, Nyst HJ, Karakullukcu B, Tan BI. Photodynamic therapy in the therapy for recurrent/persistent nasopharyngeal cancer. Head Neck Oncol. 2009;1:40.

25. You R, Zou X, Hua YJ, Han F, Li L, Zhao C, et al. Salvage endoscopic nasopharyngectomy is superior to intensitymodulated radiation therapy for local recurrence of selected T1-T3 nasopharyngeal carcinoma - a case-matched comparison. Radiother Oncol. 2015;115:399-406.

26. Kong L, Lu JJ. Reirradiation of locally recurrent nasopharyngeal cancer: history, advances, and promises for the future. Chin Clin Oncol. 2016;5:26.

27. Wu SX, Chua DT, Deng ML, Zhao C, Li FY, Sham JS, et al. Outcome of fractionated stereotactic radiotherapy for 90 patients with locally persistent and recurrent nasopharyngeal carcinoma. Int J Radiat Oncol Biol Phys. 2007;69:761-9.

28. Seo Y, Yoo H, Yoo S, Cho C, Yang K, Kim MS, et al. Robotic system-based fractionated stereotactic radiotherapy in locally recurrent nasopharyngeal carcinoma. Radiother Oncol. 2009;93:570-4.

29. Ozyigit G, Cengiz M, Yazici G, Yildiz F, Gurkaynak M, Zorlu F, et al. A retrospective comparison of robotic stereotactic body radiotherapy and three-dimensional conformal radiotherapy for the reirradiation of locally recurrent nasopharyngeal carcinoma. Int J Radiat Oncol Biol Phys. 2011;81:e263-8.

30. Orecchia R, Redda MG, Ragona R, Nassisi D, Jereczek-Fossa B, Zurrida $\mathrm{S}$, et al. Results of hypofractionated stereotactic reirradiation on 13 locally recurrent nasopharyngeal carcinomas. Radiother Oncol. 1999;53:23-8.

31. Ahn YC, Lee KC, Kim DY, Huh SJ, Yeo IH, Lim DH, et al. Fractionated stereotactic radiation therapy for extracranial head and neck tumors. Int J Radiat Oncol Biol Phys. 2000;48:501-5.

32. Xiao J, Xu G, Miao Y. Fractionated stereotactic radiosurgery for 50 patients with recurrent or residual nasopharyngeal carcinoma. Int J Radiat Oncol Biol Phys 2001;51:164-70.

33. Pai PC, Chuang CC, Wei KC, Tsang NM, Tseng CK, Chang CN. Stereotactic radiosurgery for locally recurrent nasopharyngeal carcinoma. Head Neck. 2002;24:748-53.

34. Chua DT, Sham JS, Kwong PW, Hung KN, Leung LH. Linear accelerator-based stereotactic radiosurgery for limited, locally persistent, and recurrent nasopharyngeal carcinoma: efficacy and complications. Int J Radiat Oncol Biol Phys. 2003;56:177-83.

35. Chua DT, Sham JS, Leung LH, Au GK. Re-irradiation of nasopharyngeal carcinoma with intensity-modulated radiotherapy.
Radiother Oncol. 2005;77:290-4.

36. Liu F, Xiao JP, Xu GZ, Gao L, Xu YJ, Zhang Y, et al. Fractionated stereotactic radiotherapy for 136 patients with locally residual nasopharyngeal carcinoma. Radiat Oncol. 2013;8:157.

37. Dizman A, Coskun-Breuneval M, Altinisik-Inan G, Olcay GK, Cetindag MF, Guney Y. Reirradiation with robotic stereotactic body radiotherapy for recurrent nasopharyngeal carcinoma. Asian Pac J Cancer Prev. 2014;15:3561-6.

38. Chen KC, Yen TT, Hsieh YL, Chen HC, Jiang RS, Chen WH, et al. Postirradiated carotid blowout syndrome in patients with nasopharyngeal carcinoma: a case-control study. Head Neck. 2015;37:794-9.

39. Lee AW, Foo W, Law SC, Poon YF, Sze WM, O SK, et al. Reirradiation for recurrent nasopharyngeal carcinoma: factors affecting the therapeutic ratio and ways for improvement. Int $\mathrm{J}$ Radiat Oncol Biol Phys. 1997;38:43-52.

40. Chua DT, Sham JS, Hung KN, Leung LH, Au GK. Predictive factors of tumor control and survival after radiosurgery for local failures of nasopharyngeal carcinoma. Int J Radiat Oncol Biol Phys. 2006;66:1415-21.

41. Xiao W, Liu S, Tian Y, Guan Y, Huang S, Lin C, et al. Prognostic significance of tumor volume in locally recurrent nasopharyngeal carcinoma treated with salvage intensity-modulated radiotherapy. PLoS One. 2015;10:e0125351.

42. Chua DT, Hung KN, Lee V, Ng SC, Tsang J. Validation of a prognostic scoring system for locally recurrent nasopharyngeal carcinoma treated by stereotactic radiosurgery. BMC Cancer. 2009;9:131.

43. Li YQ, Tian YM, Tan SH, Liu MZ, Kusumawidjaja G, Ong EH, et al. Prognostic model for stratification of radioresistant nasopharynx carcinoma to curative salvage radiotherapy. J Clin Oncol. 2018;36:891-9.

44. Eekers DB,RoelofsE,Jelen U,KirkM,GranzierM,AmmazzalorsoF, et al. Benefit of particle therapy in re-irradiation of head and neck patients. Results of a multicentric in silico ROCOCO trial. Radiother Oncol. 2016;121:387-94.

45. Hu J, Bao C, Gao J, Guan X, Hu W, Yang J, et al. Salvage treatment using carbon ion radiation in patients with locoregionally recurrent nasopharyngeal carcinoma: Initial results. Cancer. 2018;124:242737.

46. Gao J, Hu J, Guan X, Yang J, Hu W, Kong L, et al. Salvage carbonion radiation therapy for locoregionally recurrent head and neck malignancies. Sci Rep. 2019;9:4259. 